\author{
T.S. Hahm \\ Princeton Plasma Physics Labotatory \\ P.O. Box 451 \\ Princeton, New Jersey 08543
}

DE88 $01 \quad 323$

\begin{abstract}
Linear tearing instability is studied in the banana collisionality regime in tokamak geometry. Neoclassical effects produce significant modifications of Ohm's law and the vorticity equation so that the growth rate of te ring modes driven by $\Delta^{-}$is dramatically reduced compared to the usual resistiv. AHD value. Consequences of this result, regarding the presence of pressuregradient-driven neoclassical resistive interchange instabilities and the evolution of magnetic islands in the Rutherford regime, are discussed.
\end{abstract}

\title{
DISCLAIMER
}

This report was prepared as an account of work sponsored by an agency of the United States Government. Neither the United States Government nor any agency thereof, oor any of their bility for the accuracy, completeness, or usefulied, or assumes any legal liability or responsiprocess disclosed, or represents that its use would of any information, apparatus, product, or ence herein to any specific commercial product not infringe privalely owned rights. Refermanufacturer, or otherwise does not necessarily process, or service by trade name, trademark, mendation, or favoring by the United States Govertitute or imply its endorsement, recomand opinions of authors expressed herein do novernment or any agency thereof. The views United States Government or any agency thereof. 
Resistive MHD instabilities are closely related to the confinement of tokamak plasmas. Present-day tokamaks operate at such high temperatures that it is desirable to extend the validity regine of the resistive MHD description to the lower collisionality (banana) regime where trapped particle dynamics play an important role. Equations describing these neoclassical resistive MHD instabilities were first derived by Callen and Shaing. ${ }^{1}$ Later, Connor and Chen $^{2}$ placed the ideas of Callen and shaing on a firmer basis by systematically deriving similar equations starting from the gyrokinetic equations. They found ${ }^{1,2}$ a new trapped-particle-driven resistive interchange mode with a growth rate similar to that of the ustal resistive ballooning mode ${ }^{3}$ in the Pfirsch-Schluter regime. This new instability occurs in the typical tokamak equilibrium where the average curvature is favorable. The destablizing mechanism comes from the bootstrap current in the ohm's law coupled to the flow damping term in the vorticity equation.

Rutherford theory 4 for the nonlinear evolution of a single magnetic island also has been extended to include bootstrap current effects. 5,6 References 5 and 6 indicate that the bootstrap current is destabilizing. The analysis of Refs. 5 and 6 is valid when the magnetic island size is large enough that the inertial layer physics described by the vorticity equation is irrelevant. On the other hand, the analysis of the linear neoclassical tearing instability driven by $\Delta^{-}$has not been carried out. Reference 6 discusses a related, but different topic regarding the "tearing parity" resistive interchange mode, which is driven by the pressure gradient rather than the current density gradient $\left(\Delta^{-}\right)$.

The main purpose of this letter is to investigate the linear stability of neoclassical tearing modes. Since our final dispersion relation describes both the neoclassical tearing mode and resistive interchange mode, we can discuss the various limiting cases and elucidate the relations between them. 
We begin the analysis from the equations derived in Ref. 2, which describe the dynamics of neoclassical resistive MHD instabilities. We write Ohm's law and the vorticity equation in ballooning space separately.

$$
\begin{aligned}
& \frac{X^{2}}{Q_{e}} \frac{d \Psi}{d X}=-\frac{X}{Q_{e}}(H+L T) \phi+(1-T) \frac{d}{d X}(\phi-\Psi) . \\
& \frac{d}{d X} X^{2} \frac{d \varphi}{d X}+(L+H) X \frac{d}{d X}(\phi-\Phi) \\
&=Q Q_{i} X^{2} \phi-D \phi .
\end{aligned}
$$

In deriving Eqs. (1) and (2), a two spatial scale-length analysis (similar to that used by Glasser, Greer:, and Johnson ${ }^{7}$ ), in which the equations defined on the long resistive scale along the magnetic field line are derived through averaging over the shorter connection length scale, has been used. $\phi$ is the average perturbed electrostatic potential. $\Psi$ is the average $(D C)$ part of which is related to the perturbed vector potential hy

$$
A_{\|}=\frac{c}{i \omega} \hat{n} \cdot \nabla \bar{q} .
$$

$X$ is the normalized coordinate in the ballooning space $z ; X=z_{0} z, Q$ is the normalized growth rate; $Q=-i Q_{0} \omega, \omega$ is the mode frequency, $Q_{j}$ are the scaled versions of $\omega-\omega_{*}$, where $\omega_{* j}$ is the diamagnetic drift frequency. The normalization factors are:

$$
\begin{aligned}
& z_{0}=\left(\frac{\pi_{B} c^{2} Q^{2}\left\langle B^{2}\right\rangle}{4 \pi\left\langle B^{2} / R^{2} B_{x}{ }^{2}\right\rangle}\right) 1 / 3\left(\frac{4 \pi m_{i} n\left\langle R^{2}\right\rangle\left\langle B^{2} / R^{2} B_{x}{ }^{2}\right\rangle}{4 \pi^{2}(d q / d v)^{2}}\right) \\
& Q_{0}=\left(\frac{n_{B} c^{2} Q^{2}\left\langle B^{2}\right\rangle}{4 \pi\left\langle B^{2} / R^{2} B_{x}{ }^{2}\right\rangle}\right)^{-1 / 3}\left(\frac{4 \pi m_{i} n\left\langle R^{2}\right\rangle\left\langle B^{2} / R^{2} B_{x}{ }^{2}\right\rangle}{4 \pi^{2}(d q / d v)^{2}}\right)
\end{aligned}
$$


where $\eta_{\|}$is the classical Spitzer resistivity. Other notations are standard, as defined in Refs. 2 and 7.

Since we are considering the banana regime (rather than Pfirsch-Schiüter regime), new flux-surface-averaged quantities appear in Eqs. (1) and (2). They are:

$$
\left.I=1-\frac{3}{4}\left\langle B^{2}\right\rangle \int_{0}^{B} \max ^{-1}\left[\lambda \mathrm{d} \lambda /(1-\lambda B)^{1 / 2}\right\rangle\right]
$$

which characterizes the fraction of trapped particles, and

$$
L=\frac{I p^{\prime}}{\pi(d q / d v)} \frac{\left\langle B^{2} / R^{2} B_{x}^{2}\right\rangle}{\left\langle B^{2}\right\rangle},
$$

which characterizes the rotation damping originating from the off-diagonal components of the pressure tensor. Equation (1) is Ohn's law where the lefthand side is the parallel current written in terms of via Ampere's law. The first term on the right-hand side of Eq. (1) is a sum of the bootstrap current $(\sim L T)$ and the averaged Pfirsch-Schluter current $(-H)$. The last term describes the parallel electric field multiplied by the effective conductivity (-†-T) which is reduced by the presence of trapped particles since they do not carry charge along the magnetic field lines.

Equation (2) is the vorticity equation where the first term on the lefthand side represents the influence of field line bending which comes from the divergence of the parallel current. The second term characterizes the neoclassical flow damping originating from the off-diagonal components of the pressure tensor. On the right-hand side, the first term represents finite inertial effects assoclated with the divergence of the polarization current. 
The second term arises from the interaction of the pressure gradient with the curvature and is the measure of flux-surface-averaged curvature, which determines the Mercier stability.

Combining Eqs. (1) and (2), we obtain the following second order differential equation in terms of $\$$,

$$
\begin{aligned}
\frac{d}{d X} \frac{x^{2}}{\Gamma} \frac{d}{d X} \phi+L(1-T)\left(1-\frac{1}{\Gamma}\right) x \frac{d}{d X} \phi \\
=\phi\left\{x^{2} Q Q_{i}-D_{R}+(H / \Gamma)(H+1-2 / \Gamma)\right. \\
-[(1-1 / \Gamma)(H+T(L-1+H-2 / \Gamma)]\},
\end{aligned}
$$

where $I=1+X^{2} / Q_{e}(1-T)$. We note that in Ref. $2, I$ has been approximated by $1+x^{2} / Q_{e}$. The solution of $\mathrm{Eq}$. (3) should converge as $|x|+\infty$ and match onto the ideal MHD solution as $X+0$. The ideal MHD equation which can be recovered from Eq. (3) by taking $X \rightarrow 0$, is

$$
\frac{d}{d z} 2^{2} \frac{d}{d z} \phi+D \phi=0
$$

The large 2 asymptotic behavior of Eq. (4) is

$$
\phi-1+\frac{\Delta^{\prime}}{\pi} \frac{1}{2}
$$

when $\mathrm{D} \equiv \mathrm{D}_{\mathrm{R}}+\mathrm{H}(1-\mathrm{H}) \ll 1$, and $\Delta^{\prime}$ is the usual tearing mode stability parameter which should be obtained through a numerical solution of the ideal MHD equation. 
For typical large aspect ratio $\left(A \equiv R / r_{0}\right)$ tokamaks with nearly circular surfaces, we have ${ }^{2} D_{R} \sim a / A s^{2}, L-a A / s, H \sim a / A s$, and $T-A^{-1 / 2}$, where

$$
\alpha \equiv \frac{-4 \pi R q^{2}}{B_{o}^{2}} \frac{d p}{d r} \sim \frac{B_{p}}{A} \frac{d \ln p}{d \ln r}\left(\beta_{p} \equiv 8 \pi p / B_{x}^{2}\right)
$$

and

$$
s \equiv \frac{d \ell n g}{d \ell n r}
$$

are the pressure gradient and shear parameters with which we are familiar from ideal ballooning mode stability theory. We can see that even for moderate values of ${ }_{B}^{B}-1,\left[\right.$ is so large $(-1)$ that the inertial term $\left(-Q_{1} x^{2}\right)$ in $E q$. (3) is dominated by the neoclassical term ( $-L$ ) in Eq. (3). Hence, a major departure from the usual resistive MHD result is expected. In keeping with our objective of discussing neoclassical modification of the tearing mode, it is desirable to keep the conventional resistive MHD terms alongside the neoclassical terms. It also helps us to maintain the mathematical structure of the usual resistive MHD equations 8 and to refer to previous results. Thus, we can formally order

$$
L-Q^{3 / 2}<<9 .
$$

We keep $\mathrm{D}_{\mathrm{R}}$ in order to discuss the role of favorable average curvature, meanwhile neglecting the $H$ term whith is not the main subject of this letter. Reference 7 discusses the effect of finite $H$.

Taking advantage of the smallness of $L, Q$, and $D_{R}$, we can further identify different asymptotic regions in addition to the ideal MHD region. 
Inertial Iayer

In this region, $x^{2} \gg Q$ so that the electrostatic approximation is appropriate. Equation (3) simplifies to

$$
\begin{aligned}
& (1-T) Q_{e} \frac{d^{2}}{d x^{2}} \phi+L(1-T) x \frac{d}{d X} \phi \\
& =\phi\left\{x^{2} Q_{i}-D_{R}+L T\right\} .
\end{aligned}
$$

The solution of Eq. (6) which decays as $x \rightarrow \infty$, can be written in terms of the parabolic cylinder function $U$, i.e.,

$$
\Phi=e^{-L x^{2} / 4 Q} \mathrm{U}\left(-a, 12\left(\frac{L^{2}(1-T)+4 Q Q_{i} Q_{e}}{4 Q_{e}{ }^{2}(1-T)}\right) x\right)
$$

where

$$
a=\frac{1}{4} \frac{2 D_{R}-L(1+T)}{Q_{e}(1-T)}\left(\frac{L^{2}(1-T)+4 Q Q_{i} Q_{e}}{4 Q_{e}^{2}(1-T)}\right)^{-1 / 2}
$$

Within the ordering scheme of this work, the neoclassical modification is confined in this region. The bootstrap current contribution to Ohm's law enters into Eq. (6) through the divergence of the parallel current representing the fleld line bending. One part ( LT申) introduces the 'new' interchange-like driving force on the right-hand side. This destabilizing effect has been emphasized in the previous publications. 1,2 The rentaining part ( -LTX $d \phi / d X)$ combined with the flow damping term ( $L X d \phi / d X)$ on the left-hand side, significantly affects the usual asymptotic balance 8 of the inertia and the field line bending force due to Ohmic current. This results in the enhancement of the effective inertia $\left(4 Q Q_{i} Q_{e}-L^{2}(1-T)+4 Q Q_{i} Q_{e}\right)$ as shown in Eq. (7). This stabilizing effect, although not emphasized 
previously, reduces the growth rates of the $\Delta^{\prime}-d r i v e n$ tearing modes and introduces a stringent instability threshold condition for the neoclassical resistive interchange modes. The small-X asymptotic behavior is given by

$$
0-1-2\left(\frac{L^{2}(1-T)+4 Q Q_{1} Q_{e}}{4 Q_{e}{ }^{2}(1-T)}\right) \frac{\Gamma(3 / 4-a / 2)}{\Gamma(1 / 4-a / 2)} \times .
$$

\section{Intermediate region}

In this region, $x^{2}-Q$ so that the mode character is electromagnetic. Simplification of Eq. (3) is possible since the Inertial and interchange effects are negligible.

$$
\frac{d}{d x} \frac{x^{2}}{1+x^{2} / Q_{e}(1-T)} \frac{d \phi}{d x}=0
$$

Direct integration of Eq. (9) yields

$$
\phi=C_{0}+C_{1}\left(\frac{X}{Q_{e}(1-T)}-\frac{1}{X}\right) .
$$

The asymptotic analysis is completed by matching the small-x behavior of $\mathrm{Eq}$. (10) to Eq. (5) and the large-x behavior of Eq. (10) to Eq. (8). The desired dispersion relation for the neoclassical tearing-interchange instabilities is:

$$
\Delta^{\prime}\left(\frac{{ }_{0}}{\sqrt{2} \pi}\right)=(1-T)^{3 / 4} Q_{e}^{1 / 2}\left(L^{2}(1-T)+4 Q Q_{i} Q_{e}\right)^{1 / 4} \frac{r(3 / 4-a / 2)}{r(1 / 4-a / 2)} .
$$

The following limiting cases are discussed: 


\section{Tearing instability}

The tearing instability is driven by the current density gradient, characterized by $\Delta^{\prime}$. In this case, the "a" term in the argument of the gamma functions plays an insignificant role. For the sake of discussion, we first consider the case where the neoclassical effects can be treated perturbatively, i.e., $\mathrm{L}^{2}(1-\mathrm{T}) \ll<4 Q_{\mathbf{i}} \mathrm{Q}_{\mathbf{e}}$. In this case, $|\mathrm{a}| \ll<1$ and Eq. (11) becomes

$$
Q_{e}^{3 / 4} Q_{i}^{1 / 4} Q^{1 / 4}=\left(1+\frac{L^{2}(1-T)}{4 Q Q_{i} Q_{e}}\right)^{-1 / 4}(1-T)^{-3 / 4} \Delta^{\prime}\left(\frac{Z}{2 \pi}\right) \frac{\Gamma(1 / 4)}{\Gamma(3 / 4)}
$$

From Eq. (12), we can see that the combined effects of bootstrap current and neoclassical flow damping $\left(-L^{2}(1-T)\right)$ increase the effective inertia, and tend to suppress the tearing mode. We note that the (1-T) factor is the effective enhancement of the resistivity due to the presence of trapped particles. The previous resistive MHD results with diamagnetic effects ${ }^{9}$ are easily reccvered in the $L, T+0$ limit.

Now we examine the case where neoclassical effects dominate the dynamics $\left(L^{2}(1-T) \gg 40 Q_{1} Q_{e}\right)$, and check whether the same trend, in which the tearing mode is suppressed by the neoclassical effects, prevails. I: this case, Eq. (11) becomes

$$
\Delta^{\prime} Z_{0} / r \overline{2} \pi=(1-T) \frac{\Gamma((2-T) / 2(1-T))}{\Gamma(1 / 2(1-T))}|L|^{1 / 2} Q_{e}^{1 / 2}
$$

Equation (13) shows that the linear tearing mode growth occurs on the classical transport time scale $\left(\sim S_{R}\right)$ ! Indeed, the combined effects of the perturbed bootstrap current and the rotation damping make the linear tearing instability feeble. 


\section{Resistive interchange instability}

The resistive interchange mode is localized near a rational surface and is excited independently of the dynamics in the ideal MHD region. The dispersion relation is obtained by taking both sides of Eq. (20) to be small. From the pole of ganma function, we have $a=1 / 2+2 \mathrm{~m}$, or

$$
4 Q Q_{i} Q_{e}+L^{2}(1-T)=(1-T)^{-1}\left(L(1+T)-2 D_{R}\right)^{2} /(1+4 m)^{2}
$$

where $m$ is the radial eigenmode number. The left-hand side is the aforementioned effective inertia (note that $\mathrm{L}^{2}(1-\mathrm{T})$ is stabilizing). The righthand side is the effective driving force. For $m=0$, we have

$$
Q Q_{i} Q_{e}=(1-T)^{-1}\left(L T-D_{R}\right)\left(L-D_{R}\right)
$$

Equation (15) is essentially the same result as that of Refs. 1 and 2, apart from some minor details. We note that for most of the region in a tokamak, $L\left\langle 0, D_{R}<0\right.$ since $q^{\prime}>0, p^{\prime}\langle 0$, and $q>1$. Hence, the instability occurs when the bootstrap current contribution overcomes the stabilizing influence of favorable average curvature, i.e., $|L| T>\left|D_{R}\right|$. This threshold condition is easily satisfied in present-day tokamaks such as TFTA. Taking only dominant terms, we obtain $\mathrm{QQ}_{1} \mathrm{Q}_{e} \sim \mathrm{L}^{2} \mathrm{~T}$ so that the linear growth rate (in the absence of diamagnetic effects) scales very similarly to the usual resistive ballooning mode ${ }^{3}$ in the Pfirsch-Schlüter regime. For $t \neq 0$, the threshold condition for instability becomes $m<\left(|L| T-\left|D_{R}\right|\right) / 2|L|(1-T) \approx T / 2(1-T)$. Since $T \sim(2 / A)^{1 / 2}$, it is difficult to excite the instability with $m \geq 2$. The lowest order $(a=1)$ tearing parity interchange mode can be excited rather easily. In sumary, even in the banana regime, there exists a rather robust 
resistive interchange instability with a growth rate similar to that of the usual resistive ballooning mode. 3

Another important fact which is apparent from Eq. (14) is that the physical growth rate $\gamma\left(=Q_{0}-\ell^{1 / 3}\right)$ is maximum at an intermediate toroidal mode number \& (rather than at low $)$. For high \& modes, the diamagnetic effects $\left(-w_{*}\right)$ reduce the growth rates. This conclusion daes not apply to the tearing mode case since $\Delta^{\prime}$ is positive only for low $\ell$ modes.

In this letter, we have shown that the linear tearing mode driven by $\Delta^{\prime}$ tends to be strongly suppressed by the combined effects of rotation damping in the vorticity equation and the bootstrap current in Ohm's law. The neoclassical resistive interchange modes, however, remain relatively robust with the fastest Iinear growth occurring at intermediate values of the mode number $\ell$. We also note that the radial mode widths of the neoclassical resistive interchange modes are broader than those of Ref, 3, as shown in Eq. (7). These results are in qualitative agreement with the numerical solutions obtained from the initial value neoclassical MHD code. ${ }^{10}$ This leads us to speculate that, in banana regime plasmas, the neoclassical resistive interchange modes grow faster and dominate the nonlinear dynamics near rational surfaces. There is evidence from mixing length estimates ${ }^{6}$ that the nonlinear interactions of these neoclassical resistive intercnange $t$ odes produce a large turbulent diffusion which may lead to a significant modification of the local pressure profile and of the perturbed bootstrap current.

Of course, if a finite size magnetic island is initialized by some reason such as toroidal field errors, Rutherford-type analysis ${ }^{4}$ may apply with the bootstrap current playing a destabilizing role. 5,6 As mentioned earlier, this is because the vorticity equation becones irrelevant for finite-size, singleisland evolution. 


\section{ACKNCWLEDGMENTS}

The authar would like to thank Dr. Liu Chen for useful conversations. He also wishes to thank Dr. P.H. Diamond and Dr. J.W. Connor for their interest and valuable comments on the manuscript.

This work supported by U.S. DoE Contract DE-ACO2-76-CHO-3073. 


\section{REFERENCES}

1J.D. Callen and K.C. Shaing, Phys. Fldids 28, 1845 (1985).

2J.W. Connor and Liu Chen, Phys. Fluids 28, 2201 (1985).

3B.A. Carreras, P.H. Diamond, M. Murakami, J.L. Dunlap, J.D. Bell, H.R. Hicks, J.A. Holmes, E.A. Lazarus, V.K. Paré, P. Similon, C.E. Thomas, and R.M. Heiland, Phys. Rev. Lett. 50, 503 (1983).

${ }^{4}$ P.H. Rutherford, Phys. Eluids 16, 1903 (i973).

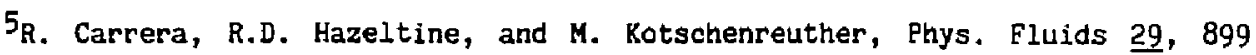
$(1986)$.

6J.D. Callen, W.X. Qu, K.D. Siebert, B.A. Carreras, K.C. Shaing, and D.A. Spong, in Plasma Physics and Controlled Nuclear Eusion Research. (IAEA, Vienna, 1987), Vol. II, p. 157.

7A.H. Glasser, J.M. Greene, and J.C. Johnson, Phys. Fluids 18, 875 (1975).

B H.P. Furth, J. Killeen, and M.N. Rosenbluth, Phys. Fluids 6, 459. (1963).

${ }^{9}$ B. Coppi, Phys, Fluids ㅇ, 2273 (1965).

${ }^{10}$ D.A. Spong, B.A. Carreras, K.C. Shaing, and J.D. Callen, presented at the Sherwood Controlled Fusion Theory Conference, 1988 (Gatlinburg, TN), abstract $1 \mathrm{~B} 1$. 
Or. Frank J. Paoloni, Uniy of Wol longong, AUSTRAL IA Prof. M, H. Brennan, Univ Sydney, AUSTRALIA

Plasma Research Lab., Australian Nat. Univ., AUSTRALIA Prot. I.R. Jones, Flinders Univ., AUSTRALIA

Prof. F. Cap, Inst Theo Phys, AUSTRIA

Prof. M. Heindler, Institut f ur Theoretische Physik, AustRiA

M. Goossans, Astronomiseh Instituut, BELGIuN

Ecole Royale Militaire, Lob de Phys Plasnas, Belgium

Comission-Eurogean, Og-XII Fusion Prog. BELGIUM

Prof. R. Boucique, Laburatoriul yoor Hetuurkunde, BELGIUM

Dr. P.H. Sakanako, Instituto Fislco, BeAzIL

Instituto De Pesquisas Espaciasi-INPE, ERAZIL

Documents Office, Atomic Energy of Canada Limited, CAMAOA

Dr. M.P. Bachynski, prg Teennologies, Inc., CANADA

Dr. H.M. Skarsgard, University of Saskatchewan, CakADA

Dr. H. Barnard, University of British Columbia, CakaDa

Prof. J. Teichmonn, Univ. of Montreal, Canado

Prof. S.R. Sreanivason, Unlversity of Calgary, CAMADA

Prof. Tudor W. Johnston, INRS-Energit, CANOA

Dr. C.R. Janes, Univ. of Alberta, CakMaA

Dr. Pater Lukẹ, Komenskeho Univ, CZECHOSLOVAKIA

The Librarian, Culha Laboratory. ENGLAND

The Librarian, Rutherford Appleton Laboratory, ENGLAND

Mrs. S.A. Hutchinson, JET Library, EHCLNo

c. Mouttat, Lab. de Physique des Militeux Ionises, France J. Radat, CEN/CADARACHE - Bat 506, FRAMcE

Univ, of loennina, Library of Physics Dept, GeEeCE

Dr. Ton Mual, Acadeny Blbliographic Ser., howg KONG

Preprint Librairy, Hungarian Acodeny of Sciances, Huker

Or. B. Dasgupta, Saha inst of Nucl. Phys., IMolA

Dr. P. Kaw, Institute for PIasso Research, IroIA

Dr. Philip Rosenau, I sroel Inst. Toch, ISRaEL

Librarian, Int'I Ctr Theo Phys, ITALY

Prof. G. Rostagni, Univ Di Padova, ITAEY

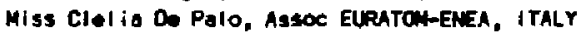

Biblioteca, Instituto di Flsica del PI asaa, I TALY

Dr. H. Yamato, Toshibo Res \& Dov, JAPAN

Prof. 1. Kawakan I, Atomic Energy Ras, Institute, JAPN

Prof. Kyoji Nishikawe, Univ of Hiroshima, JAPNN

Direc. Oept. Lorge Tokenak Res. JAERI, JAPAM

Prof. Satoshi Itoh, Kyushu University, JAPAN

Researeh Info Canter, Nagoya University, JAPAY

Prof. 5. Tanaks, Kyoto University, JAPAN

Library, Kyoto University, JAPAN

Prof. Hobuyuki Inowe, Univorsity of Tokyo, JAPAN

S. Mor $i$, JAERI, JAPAN

Librarlan, Korea Advenced Energy Res. Institute, KOREA

Prof. D.I. Choi, Adv. Inst Sel \& Tech, KofeA

Prof. B.S. Liley, University of Waikato, NEW ZEALAND

Institute of Plasma Physics, PEOPLE'S REPU⿴囗十 IC OF CHIMA

Librarian, Institute of Phys.. PEOPLE'S REPU⿴LIC Of CHIM

Library, Tsing Hue University, PEOPLE'S REPUBLlC of CHIM
2. Li, Southwast Inst. Physics, PEOPLE'S REPUBLIC Of CHINA Prot. J.A.C. Cabral, Inst Superior Tecnico, PORTUGAL Or. Octovian Petrus, AL I CUZA University, ROMANIA Or. Johon de Villiers, Fusion Studies, AEC, SO AFRICA Frof. M.A. Mellberg, University of Notal, SO AFRICA C.I.E.M.A.T., Fusion DIV. Library, SPAIN Or, Lennart Stenflo, University of UMEA, SWEDEN Library, Royal inst Tezh, SwEDEN

Prof. Hans Hilhalason, Chalmers Univ Tech, SWEDEN

Eentre Phys Jes. Plasmas, Ecole Polyteen Fod, SWITzEaLANo Bibllothesk, Fom-Inst Voor PIasma-fysica, THE NETHERLANDS Dr. O.D. Ryutov, Siberian Acad Sci, USSR

D:- G.A. El iseev, Kurshatov Institute, USSR

Dr. Y.A. Glukhikh, Inst Electrophysical Apparatus, USSR

Dr. V.T. Tolok, Inst, Phys. Tech. USSR

Dr. L.M. Kovrizhnykh, Institute Gen. Physles, USSR Nuclear Res. Establishment, Julich Ltd., W. GEPMANY Bibl jothak, Inst. Fur PI asmoforschung, W. GEFAANY Dr. K. Schindler, Ruhr Universitat Bochum, :. GEFMANY ASOEX Rading Fon, IPP/Max-PI anck-Institut f ur

PI ssmaphyslk, W. Geranky

Librarlan, Mar-PIanck Institut, H. GERMANY

Prof. R.K. Janov, Inst Phys, Yugoslavia 